\title{
Acetylbritannilactone suppresses growth via upregulation of krüppel-like transcription factor 4 expression in HT-29 colorectal cancer cells
}

\author{
XIN-MEI FANG ${ }^{1}$, BIN LIU $^{1}$, YA-BIN LIU ${ }^{2}$, JUN-JIE WANG ${ }^{1}$, JIN-KUN WEN $^{1}$, BING-HUI LI ${ }^{2}$ and MEI HAN ${ }^{1}$ \\ ${ }^{1}$ Department of Biochemistry and Molecular Biology, Institute of Basic Medicine, Key Laboratory of Medical Biotechnology \\ of Hebei Province, Key Laboratory of Neural and Vascular Biology, Ministry of Education, China; ${ }^{2}$ Department of Surgery, \\ Fourth Affiliated Hospital, Hebei Medical University, No. 361, Zhongshan East Road, Shijiazhuang 050017, P.R. China
}

Received January 27, 2011; Accepted July 4, 2011

DOI: 10.3892/or.2011.1411

\begin{abstract}
Acetylbritannilactone (ABL) is a new active compound isolated from Inula Britannica L, a traditional Chinese medicinal herb. It has been reported that ABL can inhibit the proliferation of vascular smooth muscle cells (VSMCs) and neointima formation after balloon injury in rats. ABL also shows chemopreventive properties by inducing cell apoptosis in breast and ovarian cancers, but the antitumor activity and the molecular targets of ABL in colon cancer cells have not been determined. In this study, we showed that ABL inhibits the growth in dose- and time-dependent manners by inducing cell cycle arrest in G0/G1 phase of HT-29 human colon cancer cells. This suppression was accompanied by a strong decrease of cyclin E and CDK4 protein levels, and an increase in p21 protein expression in HT-29 cells. We also show that ABL-induced growth inhibition is associated with the upregulation of KLF4 expression. The overexpression of KLF4 by infection with pAd-KLF4 resulted in growth inhibition, with decrease in the protein levels of cyclin $\mathrm{E}$ and $\mathrm{CDK} 4$, and increase in the expression of p21, similarly to the effects of ABL. Conversely, knockdown of KLF4 using a specific siRNA impaired the ABL-induced growth inhibition in HT-29 cells. These results suggest that KLF4 as an important cellular target of ABL mediates the growth
\end{abstract}

Correspondence to: Dr Bing-Hui Li, Department of Surgery, Fourth Affiliated Hospital, Hebei Medical University, No. 361, Zhongshan East Road, Shijiazhuang 050017, P.R. China

E-mail: 1bh58@hebmu.edu.cn

Professor Mei Han, Department of Bio-chemistry and Molecular Biology, Institute of Basic Medicine, Key Laboratory of Neural and Vascular Biology, China Ministry of Education, No. 361, Zhongshan East Road, Shijiazhuang 050017, P.R. China

E-mail: hanmei@hebmu.edu.cn

Key words: acetylbritannilactone, krüppel-like factor 4, cell cycle, p21WAF1/Cip1, antigrowth, mechanism, HT-29 cells inhibition of HT-29 cells induced by ABL via upregulation of p21 expression.

\section{Introduction}

Colorectal cancer is one of the leading causes of cancer death among both men and women in the world (1). Chronic or recurrent inflammation and uncontrolled cell proliferation have been strongly correlated with colorectal cancer development (2). However, limited chances for cure by chemotherapy are a major contributing factor to this situation. Despite much progress in recent years, a key problem in tumor therapy with established cytostatic compounds is the development of drug resistance and threatening side effects. Most established drugs suffer from insufficient specificity toward tumor cells. Hence, the identification of the new compounds which exert improved antitumor activity and have less toxicity is especially interest in phytochemicals and is urgently needed (3). In this regard, Chinese herbal medicine that has been practiced for thousands of years offers some unique advantages and provides a vast source of pharmaceutical material for the development of effective anticancer drugs with multiple targeting properties.

Acetylbritannilactone (ABL), a new active extract isolated from a traditional Chinese medicinal herb Inula Britannica L, is a kind of sesquiterpene (Fig. 1) and has been shown to possess anti-inflammatory and anticancer activities (4-8). Moreover, ABL has been shown to inhibit the expression of cyclooxygenase-2 (COX-2) that plays a significant role in colon carcinogenesis $(9,10)$. Our recent study revealed that one mechanism for the inhibitory effects of ABL-N, a derivative of $\mathrm{ABL}$, on breast cancer is through the activation of caspases and JNK signaling pathways, and increase in the expression of pro-apoptotic members (Bax and Bad) with a concomitant decrease in Bcl-2, subsequently inducing cell apoptosis (11). Taken together, the results suggest that ABL is an anticancer lead compound of multiple targeting molecules, and chemotherapeutics with ABL may provide a superior therapeutic strategy in the clinical setting for treatment of refractory tumors. 
Krüppel-like factor 4 (KLF4; formerly known as gutenriched Krüppel-like factor) is a zinc finger transcription factor that is highly expressed in the gastrointestinal tract (12). It has been proposed to function as a tumor suppressor and an oncoprotein, depending on cellular context. For example, overexpression of KLF4 has been linked to reduced tumorigenicity of colonic and gastric cancer cells in vivo (13). In addition, specific ablation of KLF4 in the gastric epithelium of mice results in premalignant changes, suggesting that it may be a tumor suppressor (14). Conversely, loss of KLF4 causes altered proliferation, differentiation, and precancerous changes in the adult blood vessel and stomach $(14,15)$. Reduced expression of KLF4 has been reported in human gastric cancer $(13,16)$ and restoration of KLF4 expression can induce growth arrest in vascular smooth muscle and colon cancer cells or apoptosis in gastric cancer cells $(13,17,18)$. Accumulating clinical evidence also suggests that KLF4 functions as a tumor suppressor; genetic and epigenetic alterations of the KLF4 gene have been found in colorectal cancers $(13,19,20)$. However, a role for KLF4 as an oncogene has been also supported by the induction of squamous epithelial dysplasia by ectopic KLF4 expression in mice. This paradox was partially resolved by a recent study showing that $\mathrm{p} 21^{\mathrm{WAF} 1 / \mathrm{Cip} 1}$ (p21) status may be a switch that determines the tumor suppressor or oncoprotein function of KLF4 (21).

In the present study, we investigated the expression and molecular function of KLF4 in ABL-induced growth suppression in HT-29 human colon cancer cells. Our results showed that ABL induces p21 expression and inhibits growth of HT-29 cells via upregulating KLF4 expression.

\section{Materials and methods}

Reagents. ABL was isolated by Silica gel column chromatography from Inula Britannica $\mathrm{L}$ grown in Shan-xi Province in China. ABL was characterized by nuclear magnetic resonance and mass spectroscopy. The purified ABL were dissolved in DMSO at 1,000-fold final concentration and then used to treat cells.

Adenoviral constructs. Full-length cDNA of mouse KLF4 was cloned into the replication-defective adenovirus pAd/ CMV/V5-DEST Gateway Vector (Invitrogen, Carlsbad, CA) according to the manufacturer's protocol, to obtain pAd-KLF4 that was confirmed by sequencing. An adenoviral vector (pAdnull) was used as a control virus. The resulting constructs were packaged in A293 cell (ATCC) by transfection with Lipofectamine 2000 (Invitrogen), according to the manufacturer's instructions. Culture supernatants from individual A293 cells were used to infect HT-29 cells.

Cell culture and treatment. The human HT-29 colon carcinoma cells were obtained from American Type Culture Collection and were cultured in Dulbecco's modified Eagle's medium (DMEM) with $10 \%$ fetal bovine serum, $100 \mathrm{U} / \mathrm{ml}$ penicillin, and $100 \mathrm{Ag} / \mathrm{ml}$ streptomycin. For stimulation, the cells were at $70-80 \%$ confluence and then were treated with ABL in series concentrates or infected with pAd-KLF4 at a titre of $50 \mathrm{pfu} / \mathrm{cell}$.

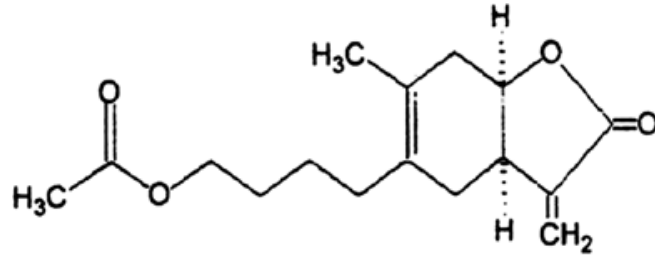

Figure 1. Chemical structure of 1-O-acetylbritannilactone.

Cell proliferation assay. HT-29 cells were seeded onto 96-well plates $\left(2 \times 10^{3}\right.$ cells per well) and treated with various concentrations of ABL for $24 \mathrm{~h}$. Proliferation was measured using MTT assay and counting cell number, respectively. The data are mean values from three different experiments.

Fluorescence activated cell sorting (FACS) analysis. HT-29 cells were collected after $24 \mathrm{~h}$ of treatment with or without of various concentrations of $\mathrm{ABL}$, fixed in $70 \%$ ethanol, washed twice with PBS, and stained with a $50 \mu \mathrm{g} / \mathrm{ml}$ propidium iodide solution containing $0.5 \%$ Triton X-100, $0.1 \mathrm{mM}$ EDTA, and $25 \mu \mathrm{g} / \mathrm{ml}$ RNase A. Fluorescence was measured and analyzed using a FACS Calibur Flow Cytometer (Becton Dickinson Immunocytometry Systems).

Western blot analysis. The protein expression for cyclin A, cyclinD1, cyclinE, CDK2, CDK4, CDK6, KLF4, p21, $\beta$-actin in HT-29 cells were examined by Western blot analysis as previously described (22). The blots were detected with the enhanced chemiluminescence detection system (Santa Cruz Biotechnology). All experiments were repeated at least three times and yielded similar results.

Immunofluorescent. Cells were fixed in $4 \%$ paraformaldehyde and permeabilized with $0.1 \%$ Triton X-100 at room temperature for $20 \mathrm{~min}$. Thereafter, cells were incubated with anti-KLF4 antibody and further stained with appropriate TRITCconjugated secondary antibody (Santa Cruz, CA). Confocal microscopy was performed with the Confocal Laser Scanning Microscope Systems (Leica).

Small interfering RNA (siRNA) transfection. The siRNAs targeting KLF4 (KLF4 siRNA) (sc-35480) and control siRNA were purchased from Santa Cruz, and then were transiently transfected into HT-29 cells using Lipofectamine 2000 (Invitrogen) following the manufacturer's protocol. KLF4 protein levels were assessed by Western blotting to confirm adequate silencing of KLF4.

Data analysis. All of the experiments were repeated at least three times with a similar pattern of results. Data are expressed as the mean $\pm \mathrm{SE}$, and the effects of ABL treatment were analyzed by Student's t-test using SPSS 13.0 software (SPSS Inc., Chicago, IL) and multiple comparisons using ANOVA. $p<0.05$ was considered to be statistically significant.

\section{Results}

$A B L$ inhibits the growth of HT-29 cells in a time- and dosedependent manner. Previous studies have demonstrated that 

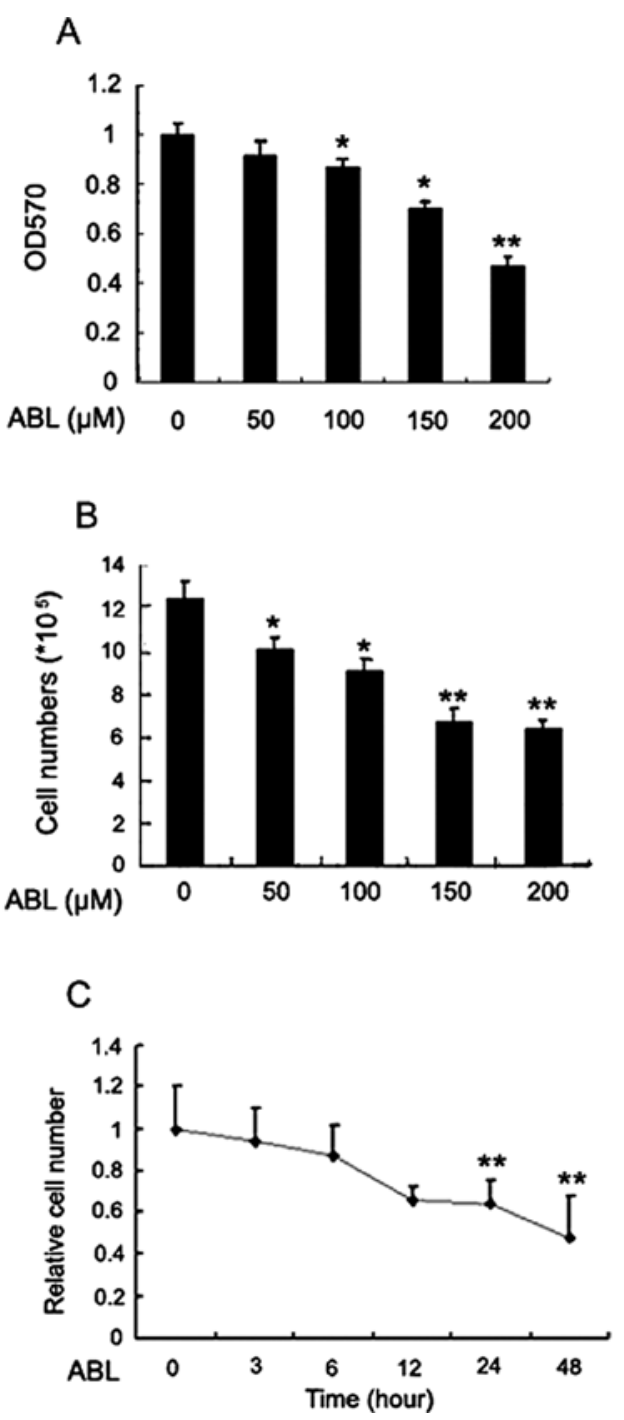

Figure 2. ABL inhibits HT-29 cells proliferation. (A) The MTT assays. HT-29 cells were treated by various concentrations of ABL for $48 \mathrm{~h}$. (B) Cell counting. HT-29 cells were treated by various concentrates of ABL for $24 \mathrm{~h}$. (C) Cell counting of HT-29 cells treated by ABL $(150 \mu \mathrm{mol} / \mathrm{l})$ for 3 to $48 \mathrm{~h}$. " $<<0.05$ or ${ }^{* *} \mathrm{p}<0.01$, compared with the cells without ABL treatment $(\mathrm{n}=5)$.

ABL inhibits the inflammation, proliferation and neointimal formation in VSMCs and induces cell apoptosis in breast and ovarian cancers $(5,7)$. In the present study, we initially tested antiproliferative effect of on human HT-29 colon carcinoma cells using MTT and cell counting assays. HT-29 cells were plated in a 96-well plate, and then treated by different concentrations $(0-200 \mu \mathrm{M})$ of ABL for $24 \mathrm{~h}$. The results showed that ABL $(0,50,100,150,200 \mu \mathrm{M})$ treatment dose-dependently reduced the activity of cell proliferation (Fig. 2A and B). Higher concentrations of ABL (100-200 $\mu \mathrm{M})$ almost completely inhibited the cell proliferation $(\mathrm{p}<0.05)$ (Fig. 2A). The results from cell counting were in agreement with MTT assay. Under the same conditions, the cell number decreased by 40,52, 64 and 76\%, compared with the control group, respectively (Fig. 2B). The $\mathrm{IC}_{50}$ value (concentration needed for $50 \%$ growth inhibition) of ABL was $\sim 95 \mu \mathrm{M}$ under the present experimental conditions. When HT-29 cells were treated with ABL $(150 \mu \mathrm{M})$ for different times, the time-dependent reduction was observed in the cell viability as compared with the untreated cells (Fig. 2C). All of these data suggest that $\mathrm{ABL}$ can exert its growth inhibitory effect in HT-29 cells.

$A B L$ arrests the cell cycle progression in HT-29 cells. To determine the effect of ABL on cell cycle progression, HT-29 cells were treated with 50-200 $\mu \mathrm{M}$ ABL for $24 \mathrm{~h}$, and then subjected to flow cytometric analysis. Data showed that ABL dose-dependently reduced the number of $\mathrm{S}$ phase cells and increased the G0/G1 phase cells ( $\mathrm{p}<0.05$ ) (Fig. 3A). The results suggested that the cell cycle of HT-29 cells was arrested in the G0/G1 phase by ABL. Cell cycle progression is controlled by cyclins and CDKs (23). To determine the expression of cyclins and CDKs in ABL-treated HT-29 cells, the lysates of the cells were analyzed by Western blotting. Treatment with ABL (50-200 $\mu \mathrm{M})$ reduced expression of cyclin E and $\mathrm{CDK} 4$, in a concentration-dependent manner with complete inhibition at $100 \mu \mathrm{M}$ (Fig. 3B and C). Conversely, CDK inhibitor p21 level in HT-29 cells was upregulated under the same conditions (Fig. 3D). However, the levels of cyclin A, cyclin D, CDK2 and CDK6 proteins were not affected by ABL treatment. These results suggest that ABL arrests cell cycle progression in G0/G1 phase through accumulating p21 protein and inhibiting cycin E and CDK4 expression.

ABL induces KLF4 expression in HT-29 cells. Recent evidence has implicated KLF4 as a central regulator of proliferation in various normal and malignant cells. Several proteins regulated by KLF4 such as p21, cyclin E are also targeted by ABL $(4,24)$. Thus, we hypothesized that ABL may reduce proliferation by promoting the KLF4 activity. For this, we first measured the expression of KLF4 protein in ABL-treated cells. After an overnight serum starvation, the cells were treated with $\mathrm{ABL}$ at different concentration for 24 h. As shown in Fig. 4A, KLF4 level in HT-29 cells increased in a dose-dependent manner with ABL treatment. Similar results were observed by immnofluorescent. The increased KLF4 protein was mainly located in the nucleus of HT-29 cells and associated with growth inhibition (Fig. 4B). Therefore, we speculated that KLF4 may be involved in ABL-induced growth inhibition in HT-29 cells.

KLF4 is involved in ABL-induced growth inhibition of HT-29 cells. To distinguish the above-mentioned possibilities, we evaluated for possible alterations of the cell proliferation in response to overexpression of KLF4. HT-29 cells were first infected with either pAd-KLF4 or Ad-null for $48 \mathrm{~h}$. The MTT assay showed that the proliferation of HT-29 cells was inhibited by the overexpression of KLF4 in a concentrationdependent manner (Fig. 5A), similar to ABL effect. However, overexpression of KLF5 did not inhibit the cell growth (data not shown). Furthermore, we investigated the effects of KLF4 overexpression on the expression of cell cycle-related proteins using Western blot analysis. The results showed that overexpression of KLF4 resulted in the decrease in cyclin E and CDK4 protein levels, and an increase in the expression of p21 protein (Fig. 5B). To confirm whether KLF4 is necessary for ABL-induced growth arrest of HT-29 cells, we examined the effects of KLF4 knockdown by specific siRNA. The results showed that inhibiting of KLF4 expression impaired 

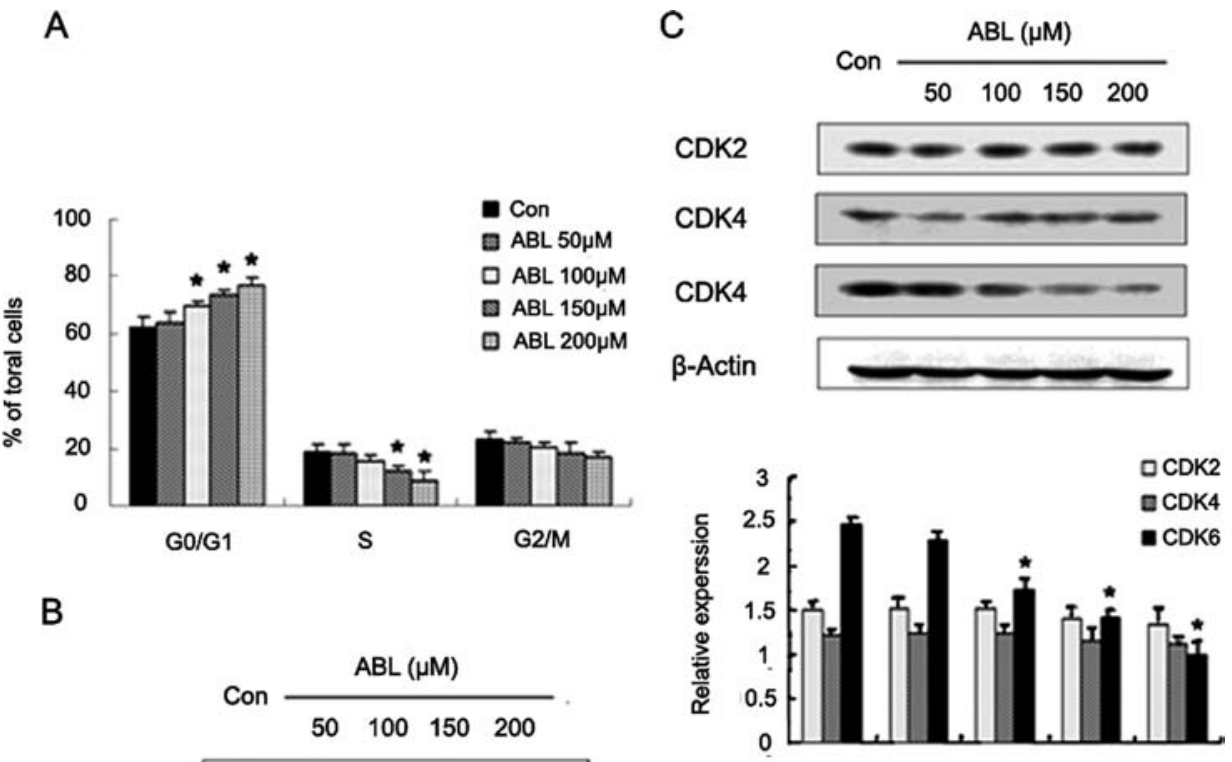

B
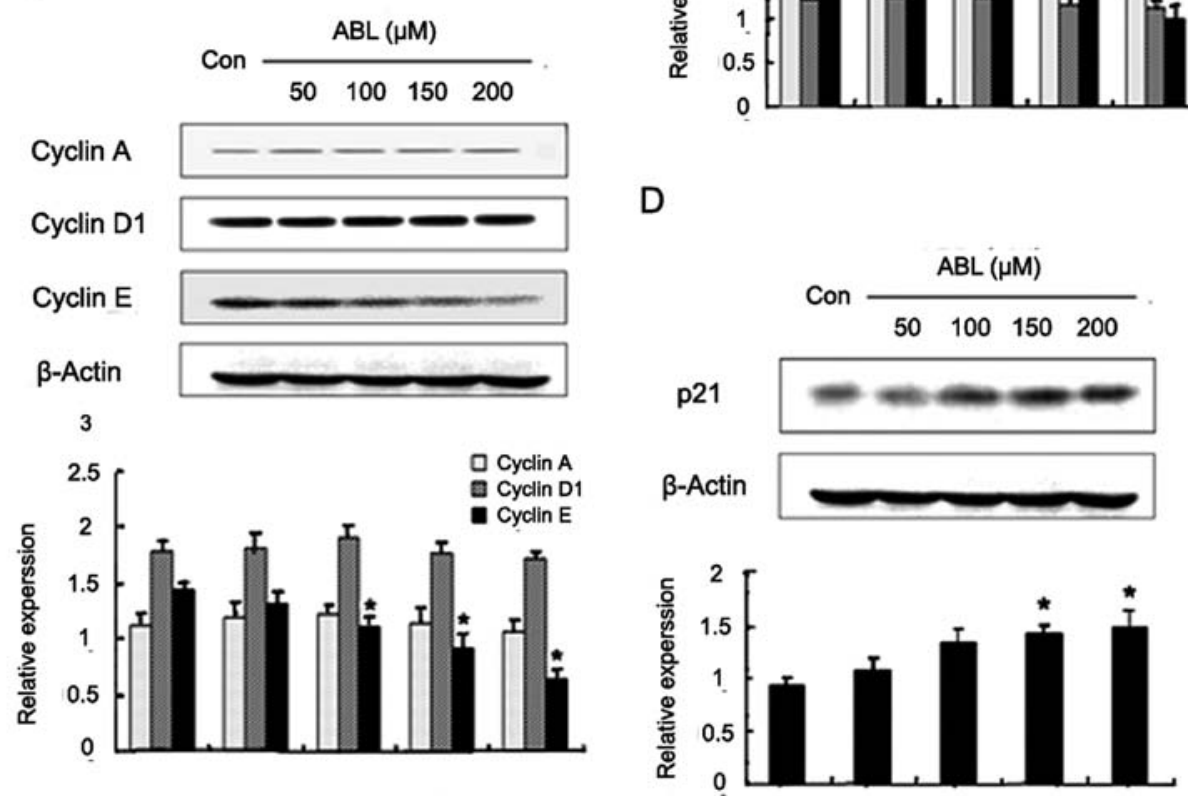

Figure 3. ABL inhibits expression of cyclin E and CDK4, and increases the expression of p21. (A) Flow cytometric analysis. HT-29 cells were treated by $\mathrm{ABL}$ at indicated concentration for $24 \mathrm{~h}(\mathrm{n}=3)$. (B-D) Western blotting for cyclins, CDKs and p21 proteins. HT-29 cells were treated by ABL at the indicated concentration for $24 \mathrm{~h}$. $\beta$-actin was used as an internal control. The graphs represent the relative level of these proteins for four independent experiments. * $\mathrm{p}<0.05$, compared with the control.

A

$$
\text { Con } \frac{\mathrm{ABL}(\mu \mathrm{M})}{50 \quad 100 \quad 150 \quad 200}
$$

KLF4

$\beta$-Actin
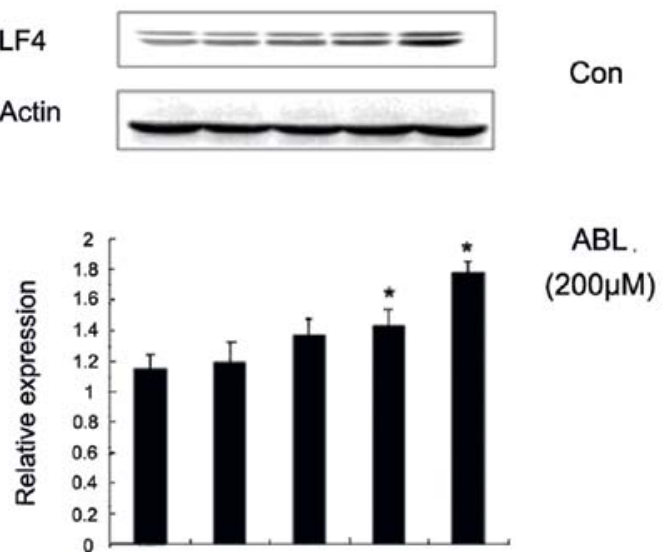

B

Con
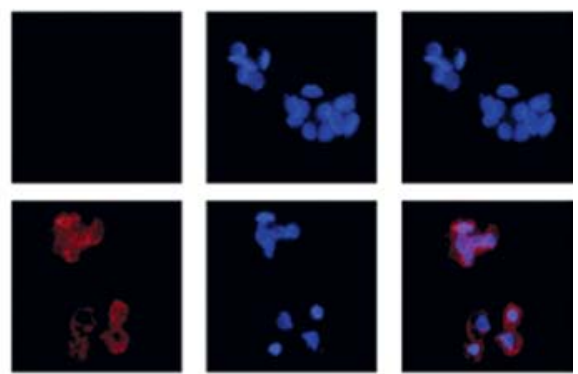

DAPI

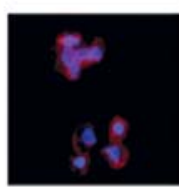

KLF4

Merged

Figure 4. ABL induces KLF4 expression in HT-29 cells. (A) Western blotting. HT-29 cells were treated by ABL at indicated concentration for $24 \mathrm{~h}$. $\beta$-actin was used as an internal control. The graphs represent the relative level of KLF4 protein for four independent experiments. " $\mathrm{p}<0.05$, compared with the control. (B) Immunofluorescent staining (x200 magnification). 


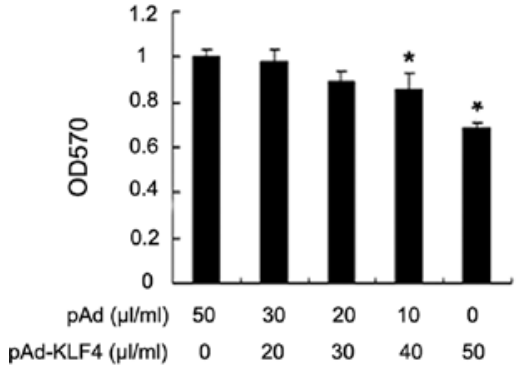

C
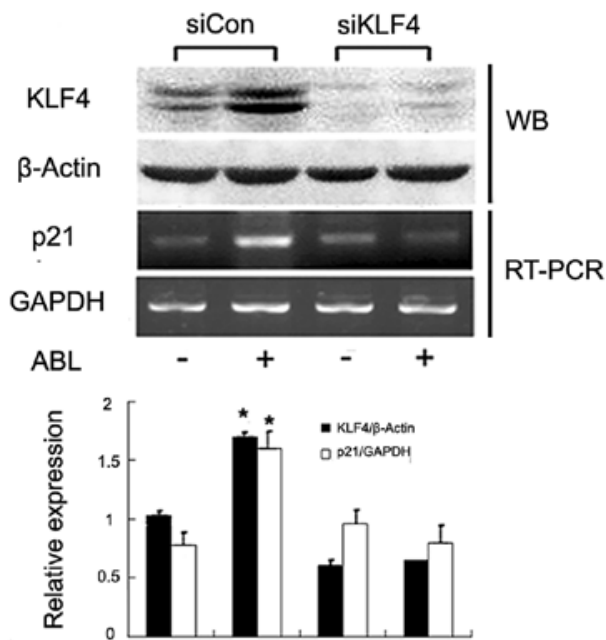

D

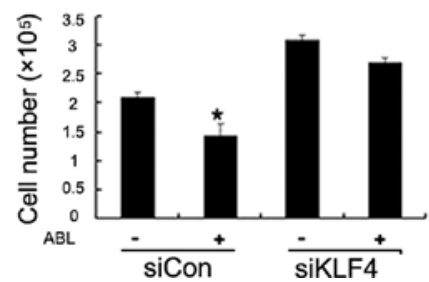

B
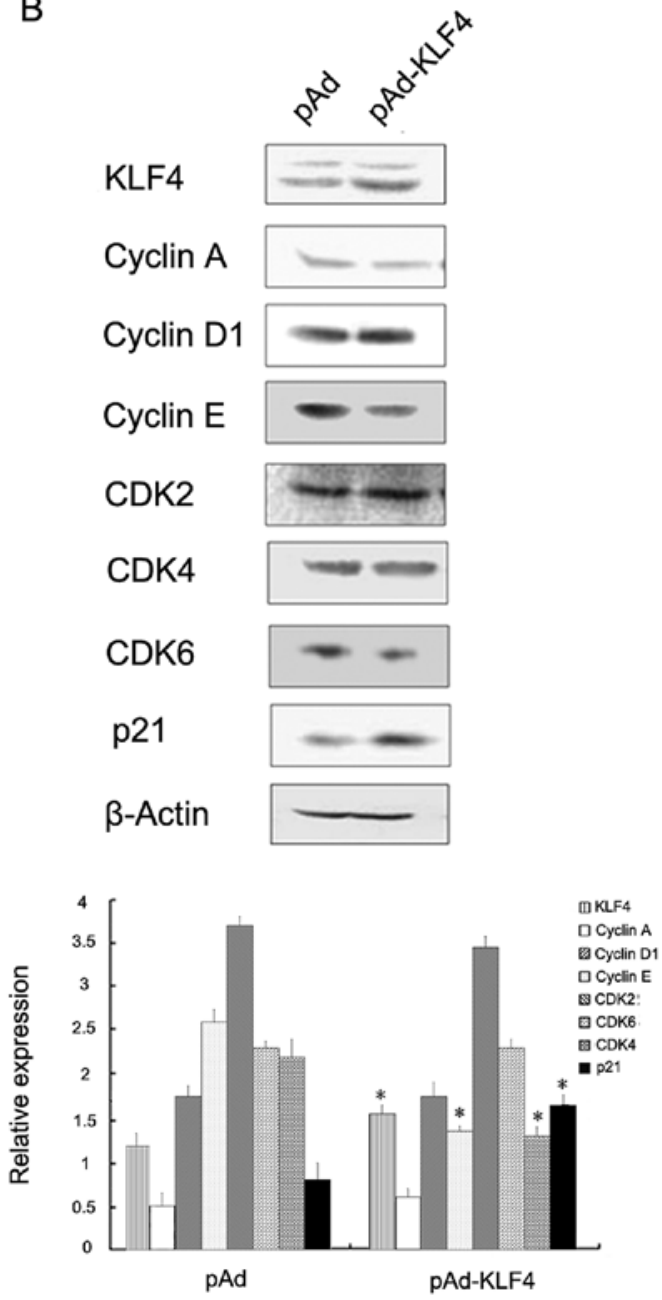

Figure 5. KLF4 is involved in ABL-induced growth inhibition of HT-29 cells. (A) The MTT assay. Cells were infected with the indicated titers of pAd-KLF4 for $48 \mathrm{~h}$. Values are mean $\pm \mathrm{SD}$ from three different experiments. " $\mathrm{p}<0.05$, compared with $\mathrm{pAd}(\mathrm{n}=3)$. (B) Western blotting. Cells were infected with pAdKLF4 for $48 \mathrm{~h}$. The graphs represent the relative level of these proteins for four independent experiments. " $\mathrm{p}<0.05$, compared with pAd. (C) Western blotting (WB) of KLF4 expression (upper panel), and semi-quantitative RT-PCR of p21 mRNA (lower panel). Cells were infected with siKLF4 for $48 \mathrm{~h}$ and then treated with ABL $(150 \mu \mathrm{mol} / \mathrm{l})$ for another $24 \mathrm{~h}$. The graphs represent the relative level of KLF4 protein and $21 \mathrm{mRNA}$ for four independent experiments. (D) Cell counting. Cells were infected with siKLF4 for $48 \mathrm{~h}$ and then treated with ABL (150 $\mu \mathrm{mol} / \mathrm{l})$ for another $24 \mathrm{~h}$. Values are mean \pm SD from three different experiments $(n=3)$. ${ }^{*}<<0.05$, compared with HT-29 cells treated without ABL.

the growth suppression induced by ABL with reduction of $\mathrm{p} 21$ protein level (Fig. 5C). Taken together, these results indicate that KLF4 mediates the growth arrests in HT-29 cells induced by ABL.

\section{Discussion}

KLF4 has been recognized as a key therapeutic target for the treatment of several types of cancer since it is a central hub for regulation of cellular processes that are critical for growth and metastasis of human cancers $(25,26)$. Herein, we show that ABL reduced proliferation of HT-29 CRC cells in dose- and time-dependent manners. This prompted us to further study the effect of ABL on KLF4 expression since the anticancer mechanism of ABL remains to be fully elucidated. To this end, we found that ABL induced expression of KLF4 and p21 proteins, as well as downregulation of cyclin E and CDK4 level. Therefore, the antiproliferative effects of ABL in HT-29 cells may be mediated by induction of the KLF4 activity and downstream KLF4-mediated p21 mRNA transcription $(21,27)$.

Previous studies indicate that KLF4 inhibits cell proliferation by activating crucial checkpoints in the cell cycle on overexpression of exogenous KLF4 or following DNA damage $(28,29)$. A critical transcriptional target of KLF4 in these conditions is the cyclin-dependent inhibitor, p21 (28-30). These findings led to the suggestion that KLF4 may function as a tumor suppressor in colorectal cancer. 
In cell culture, KLF4 expression can be increased by serum deprivation, contact inhibition, and DNA damage $(31,32)$. Conversely, reduced expression of KLF4 has been reported in various tumors $(13,14)$, and restoration of KLF4 expression can induce growth arrest in colon cancer cells (18). Inhibition of KLF4 gene expression plays a critical role in homeostasis of the normal intestine and in tumorigenesis of colorectal cancers $(33,34)$, suggesting that KLF4 is important in tumor development and progression. Biochemical studies indicate that KLF4 inhibits cell proliferation by blocking progression of the cell cycle at the G1-S and G2-M transitions (31). Studies also show that expression of KLF4 is reduced in colorectal neoplasia including carcinoma and adenoma relative to normal mucosa $(20,35)$. KLF4 has been shown to activate p21 expression (36). In the present study, we showed that increase in KLF4 levels in ABL-treated HT-29 cells was accompanied by an increase in the levels of p21, a downstream mediator of the cell cycle effect of KLF4 (28). Several lines of evidence from our and other studies indicate that p21 is a downstream target of KLF4 (25). In HT-29 cells, overexpression of KLF4 induces p21 expression, which is accompanied by a decrease in the rate of proliferation, and reduction of cyclin E and CDK4 protein levels. Conversely, inhibition of KLF4 by siRNA against KLF4 results in a decrease in p21 expression and an increase in cellular proliferation. Importantly, the increase in KLF4 is correlated with the antitumor activity of ABL in HT-29 cells. In view of the established inhibitory effect of KLF4 on cell proliferation, it is likely that KLF4 is responsible at least in part for the antiproliferation activity of ABL in HT-29 cells.

In summary, we show that the antiproliferative effect of ABL may be mediated by induction of KLF4 expression. ABL produces a dose-dependent increase of KLF4 protein level. Surprisingly, ABL results in a dose-dependent decrease of cyclin E and CDK4 level; this effect may be attributed to a dose-dependent increase in p21 mRNA and protein levels induced by ABL and/or KLF4, suggesting the KLF4 as an important cellular target of ABL in HT-29 cells. The fact that $\mathrm{ABL}$ is able to target the human colon tumor KLF4 and inhibits human colon tumor cell growth provides a strong impetus for using ABL as a chemopreventative and/or chemotherapeutic agent for human colon cancer.

\section{Acknowledgements}

This study was supported by the National Natural Science Foundation of China (30973820 and 31071003), the Hebei Province Technology Support Program (09276406D) and the Hebei Province Natural Science Foundation (C2007000831).

\section{References}

1. Cubas R, Li M, Chen C and Yao Q: Colorectal cancer: new advances in immunotherapy. Cancer Biol Ther 6: 11-17, 2007.

2. Fernandez-Majada V, Aguilera C, Villanueva A, et al: Nuclear IKK activity leads to dysregulated notch-dependent gene expression in colorectal cancer. Proc Natl Acad Sci USA 104: 276-281, 2007.

3. Surh YJ: Cancer chemoprevention with dietary phytochemicals. Nat Rev Cancer 3: 768-780, 2003.
4. Liu B, Han M and Wen JK: Acetylbritannilactone inhibits neointimal hyperplasia after balloon injury of rat artery by suppressing nuclear factor- $\{\mathrm{kappa}\} \mathrm{B}$ activation. J Pharmacol Exp Ther 324: 292-298, 2008.

5. Liu YP, Wen JK, Zheng B, Zhang DQ and Han M: Acetylbritannilactone suppresses lipopolysaccharide-induced vascular smooth muscle cell inflammatory response. Eur J Pharmacol 577: 28-34, 2007.

6. Bai N, Lai CS, He K, et al: Sesquiterpene lactones from Inula britannica and their cytotoxic and apoptotic effects on human cancer cell lines. J Nat Prod 69: 531-535, 2006.

7. Rafi MM, Bai NS, Chi Tang H, et al: A sesquiterpenelactone from Inula britannica induces anti-tumor effects dependent on Bcl-2 phosphorylation. Anticancer Res 25: 313-318, 2005.

8. Park EJ and Kim J: Cytotoxic sesquiterpene lactones from Inula britannica. Planta Med 64: 752-754, 1998.

9. Han M, Wen JK, Zheng B and Zhang DQ: Acetylbritannilatone suppresses NO and PGE2 synthesis in RAW 264.7 macrophages through the inhibition of iNOS and COX-2 gene expression. Life Sci 75: 675-684, 2004.

10. Voutsadakis IA: Pathogenesis of colorectal carcinoma and therapeutic implications: the roles of the ubiquitin-proteasome system and Cox-2. J Cell Mol Med 11: 252-285, 2007.

11. Liu B, Han M, Sun RH, et al: ABL-N-induced apoptosis in human breast cancer cells is partially mediated by c-Jun NH2-terminal kinase activation. Breast Cancer Res 12: R9, 2010.

12. Shields JM, Christy RJ and Yang VW: Identification and characterization of a gene encoding a gut-enriched Kruppellike factor expressed during growth arrest. J Biol Chem 271: 20009-20017, 1996.

13. Wei D, Gong W, Kanai M, et al: Drastic down-regulation of Kruppel-like factor 4 expression is critical in human gastric cancer development and progression. Cancer Res 65: 2746-2754, 2005.

14. Katz JP, Perreault N, Goldstein BG, et al: Loss of Klf4 in mice causes altered proliferation and differentiation and precancerous changes in the adult stomach. Gastroenterology 128: 935-945, 2005.

15. Wang C, Han M, Zhao XM and Wen JK: Kruppel-like factor 4 is required for the expression of vascular smooth muscle cell differentiation marker genes induced by all-trans retinoic acid. J Biochem 144: 313-321, 2008.

16. Yang Y, Goldstein BG, Chao HH and Katz JP: KLF4 and KLF5 regulate proliferation, apoptosis and invasion in esophageal cancer cells. Cancer Biol Ther 4: 1216-1221, 2005.

17. Zheng B, Han M, Bernier M, et al: Kruppel-like factor 4 inhibits proliferation by platelet-derived growth factor receptor beta-mediated, not by retinoic acid receptor alpha-mediated, phosphatidylinositol 3-kinase and ERK signaling in vascular smooth muscle cells. J Biol Chem 284: 22773-22785, 2009.

18. Dang DT, Chen X, Feng J, Torbenson M, Dang LH and Yang VW: Overexpression of Kruppel-like factor 4 in the human colon cancer cell line RKO leads to reduced tumorigenicity. Oncogene 22: 3424-3430, 2003.

19. Zhang W, Chen X, Kato Y, et al: Novel cross talk of Kruppellike factor 4 and beta-catenin regulates normal intestinal homeostasis and tumor repression. Mol Cell Biol 26: 2055-2064, 2006.

20. Zhao W, Hisamuddin IM, Nandan MO, Babbin BA, Lamb NE and Yang VW: Identification of Kruppel-like factor 4 as a potential tumor suppressor gene in colorectal cancer. Oncogene 23: 395-402, 2004.

21. Rowland BD, Bernards R and Peeper DS: The KLF4 tumour suppressor is a transcriptional repressor of p53 that acts as a context-dependent oncogene. Nat Cell Biol 7: 1074-1082, 2005.

22. Dong LH, Wen JK, Liu G, et al: Blockade of the Ras-extracellular signal-regulated kinase $1 / 2$ pathway is involved in smooth muscle 22 alpha-mediated suppression of vascular smooth muscle cell proliferation and neointima hyperplasia. Arterioscler Thromb Vasc Biol 30: 683-691, 2010.

23. Mitchell C, Yacoub A, Hamed H, et al: Inhibition of MCL-1 in breast cancer cells promotes cell death in vitro and in vivo. Cancer Biol Ther 10: 903-917, 2010.

24. Zheng B, Han M and Wen JK: Role of Kruppel-like factor 4 in phenotypic switching and proliferation of vascular smooth muscle cells. IUBMB Life 62: 132-139, 2010. 
25. Ghaleb AM, Aggarwal G, Bialkowska AB, Nandan MO and Yang VW: Notch inhibits expression of the Kruppel-like factor 4 tumor suppressor in the intestinal epithelium. Mol Cancer Res 6: 1920-1927, 2008.

26. Wei D, Kanai M, Jia Z, Le X and Xie K: Kruppel-like factor 4 induces p27Kipl expression in and suppresses the growth and metastasis of human pancreatic cancer cells. Cancer Res 68: 4631-4639, 2008.

27. Guo Y, Costa R, Ramsey H, et al: The embryonic stem cell transcription factors Oct-4 and FoxD3 interact to regulate endodermal-specific promoter expression. Proc Natl Acad Sci USA 99: 3663-3667, 2002.

28. Chen X, Johns DC, Geiman DE, et al: Kruppel-like factor 4 (gut-enriched Kruppel-like factor) inhibits cell proliferation by blocking G1/S progression of the cell cycle. J Biol Chem 276: 30423-30428, 2001.

29. Yoon HS, Chen X and Yang VW: Kruppel-like factor 4 mediates p53-dependent G1/S cell cycle arrest in response to DNA damage. J Biol Chem 278: 2101-2105, 2003

30. Chen X, Whitney EM, Gao SY and Yang VW: Transcriptional profiling of Kruppel-like factor 4 reveals a function in cell cycle regulation and epithelial differentiation. J Mol Biol 326 665-677, 2003
31. Yoon HS and Yang VW: Requirement of Kruppel-like factor 4 in preventing entry into mitosis following DNA damage. J Biol Chem 279: 5035-5041, 2004

32. Chen ZY, Wang X, Zhou Y, Offner G and Tseng CC: Destabilization of Kruppel-like factor 4 protein in response to serum stimulation involves the ubiquitin-proteasome pathway. Cancer Res 65: 10394-10400, 2005.

33. Nakamura T, Tsuchiya $\mathrm{K}$ and Watanabe M: Crosstalk between Wnt and Notch signaling in intestinal epithelial cell fate decision. J Gastroenterol 42: 705-710, 2007.

34. Di Valentin E, Crahay C, Garbacki N, et al: New asthma biomarkers: lessons from murine models of acute and chronic asthma. Am J Physiol Lung Cell Mol Physiol 296: L185-L197, 2009.

35. Wei D, Kanai M, Huang S and Xie K: Emerging role of KLF4 in human gastrointestinal cancer. Carcinogenesis 27: 23-31, 2006.

36. Zhang W, Geiman DE, Shields JM, et al: The gut-enriched Kruppel-like factor (Kruppel-like factor 4) mediates the transactivating effect of $\mathrm{p} 53$ on the p21WAF1/Cip1 promoter. J Biol Chem 275: 18391-18398, 2000. 